\title{
Show Me the Money: On Predicting Actual Purchases in Cross-National Sponsorship
}

\author{
Noni Zaharia ${ }^{1}$, Simon Brandon-Lai ${ }^{2} \&$ Jeffrey James ${ }^{3}$ \\ ${ }^{1}$ Erivan K. Haub School of Business, Saint Joseph's University, Philadelphia, PA, USA \\ ${ }^{2}$ School of Professional Studies, SUNY Cortland, Cortland, NY, USA \\ ${ }^{3}$ The Department of Sport Management, Florida State University, Tallahassee, FL, USA \\ Correspondence: Noni Zaharia, Erivan K. Haub School of Business, Saint Joseph’s University, Philadelphia, PA, \\ USA. E-mail: czaharia@sju.edu
}

Received: July 10, 2017 Accepted: July 25, $2017 \quad$ Online Published: July 28, 2017

doi:10.5539/ijms.v9n4p38 URL: http://doi.org/10.5539/ijms.v9n4p38

\begin{abstract}
The improvements in new media technologies in conjunction with the expansion of innovative opportunities for marketing and consuming sport have played direct roles in the globalization of sport. However, those in the Sport Management academic field are still trying to understand the effect of culture on sport consumer behavior. Guided by Hofstede's cultural dimensions theory, the purpose of this study was to examine the sponsorship and cross-national relationships among the short-term/long-term orientation and individualism/collectivism cultural dimensions, attitude toward a sponsor, gratitude, purchase intentions, and actual purchases. Data were collected via longitudinal web surveys conducted with soccer fans from the United States, the United Kingdom, and India. The results from a structural equation model provided evidence that the individualism/collectivism cultural dimension had a significant effect on gratitude but not on actual purchases, and that the purchase intentions variable was a predictor of actual purchases.
\end{abstract}

Keywords: global, Hofstede, United States, United Kingdom, India

\section{Introduction}

The magnitude of sport sponsorship has risen steadily in recent decades, with companies now allocating in excess of $\$ 60$ billion globally (IEG, 2016). Rapid and ongoing development of new media technologies (e.g., broadband and mobile platforms) has reduced distances between international markets, and organizations-including sports teams-have become truly global brands (Amis \& Cornwell, 2005; Santomier, 2008). For example, the English Premier League (EPL) is shown in 212 territories around the world by 80 different broadcasters, attracting a total audience of approximately 4.7 billion ("Premier League," n.d., para. 2). As such, sports teams are ideal vehicles for sponsors that seek to reach international audiences.

Despite the global nature of sport sponsorships, there appears to be little research in which scholars have assessed the cross-national effectiveness of such agreements (Amis \& Cornwell, 2005; Yoshida \& Heere, 2015). In particular, jersey sponsorship-ubiquitous in Europe and Asia-is a growing revenue source in specific sport segments (Biscaia, Correia, Ross, \& Rosado, 2014; Breuer \& Rumpf, 2012). This is exemplified by the EPL team Manchester United's jersey sponsorship deal with the United States (U.S.) car manufacturer Chevrolet, signed in 2014, estimated at $\$ 1.3$ billion over ten years (Thompson, 2014). Jersey sponsorships are also intriguing as, unlike other forms of sponsorship (e.g., broadcast partners, in-game sponsors), they are visible to all consumers in the same manner, irrespective of their geographic location. Upon review, there was a lack of research in which scholars have empirically analyzed the cross-national effectiveness of jersey sponsorship. Given the magnitude and prevalence of this type of sponsorship, it is important that sport marketers understand their effects on global consumer groups.

However, evaluating the effectiveness of such sponsorships presents a further challenge to sport marketing scholars. The question still remains on how one can interpret findings based on cross-national data (Yoshida \& Heere, 2015). Thus, in this study the researchers included the short-term/long-term orientation cultural dimension (e.g., values such as perseverance, stability and respect for traditions; Hofstede, Hofstede, \& Minkov, 2010), and the individualism/collectivism cultural dimension (i.e., the degree to which individuals are 
self-centered or integrated into groups; Hofstede et al., 2010) from Hofstede's cultural dimensions theory. Previous research on cross-national consumer behavior has utilized Hofstede's cultural dimensions theory (De Mooij \& Hofstede, 2010; Singh, 2006), which reflects aspects of a culture that can be measured relative to other cultures (e.g., scales from 0 for the most collectivist and short-term orientation country to 100 for the most individualist and long-term orientation one; Hofstede et al., 2010). To the researchers' knowledge, there have been no academic studies that have included Hofstede's cultural dimensions variables in a sport context.

Moreover, despite an increasing number of studies measuring sponsorship outcomes such as attitude toward the sponsor and purchase intentions (e.g., Alexandris, Tsiotsou, \& James, 2012; Biscaia, Correia, Rosado, Ross, \& Maroco, 2013), there is a need for established theoretical frameworks explaining consumer decision-making that include variables such as gratitude and actual purchase behaviors (e.g., Kim, Lee, Magnusen, \& Kim, 2015; Kim, Smith, \& James, 2010; Mazodier \& Merunka, 2012). Gratitude is believed to play an important role in understanding how marketing investments increase purchase intentions and sales growth (Palmatier, Jarvis, Bechkoff, \& Kardes, 2009). In addition, although intent to purchase is commonly used in the sponsorship academic literature, a more accurate assessment of consumer behavior would include measuring actual purchase data (Gwinner \& Bennett, 2008; Kim et al., 2015; Mazodier \& Merunka, 2012). However, longitudinal research is needed if, for example, scholars are to understand the extent to which attitude toward a sponsor, and purchase intentions influence actual purchase behavior (Funk, Mahony, \& Havitz, 2003; Yoshida \& Heere, 2015; Yoshida, Heere, \& Gordon, 2015). In this study the researchers also employed two demographics information (i.e., annual household income and household's decision maker) as control variables because scholars have found that they may predict actual purchase behavior (Armstrong, 1985; Sun \& Morwitz, 2010).

The purpose of this study was to examine the sponsorship and cross-national relationships among the short-term/long-term orientation and individualism/collectivism cultural dimensions, attitude toward a sponsor, gratitude, purchase intentions, and actual purchases, controlling for the annual household income and household's decision maker. In doing so, the researchers believe there are three important contributions to the Sport Management literature: (1) extension of cross-national research on sponsorship effectiveness, (2) examination of jersey sponsorship specifically, due to the prevalence of this type of sponsorship at a global level, and (3) evaluation of sponsorship effectiveness using a potentially more robust outcome, actual purchase behavior. This research initiative was addressed by analyzing responses from soccer fans from the United States, the United Kingdom (U.K.), and India in the area of a sport sponsorship through a jersey sponsorship.

\section{Theoretical Framework and Literature Review}

\subsection{Cultural Dimensions}

Hofstede's cultural dimensions theory was the theoretical framework utilized in this study, as much of the research on cross-national consumer behavior has utilized these dimensions, which reflect aspects of a culture that can be measured relative to other cultures (i.e., individualism/collectivism, short/long-term orientation, power distance, masculinity/femininity, uncertain avoidance, and indulgence/restraint; Hofstede et al., 2010). Hofstede defined culture as "the collective programming of the mind that distinguishes the members of one group or category of people from another" $(2001$, p. 9).

Although countries' cultural scores originally were produced in the early 1970s, many replications of Hofstede's study of different samples have provided evidence that the country ranking in his data is still valid (Hofstede et al., 2010). A benefit of Hofstede's cultural dimensions rests in being able to explain and compare aggregate national behavior (Magnusson, Wilson, Zdravkovic, Zhou, \& Westjohn, 2008; Singh, 2006). Moreover, Hofstede has shown more than 400 significant correlations between his index scores and data from other sources that validate them (Hofstede, 2001). Hofstede initially created four dimensions (there are now six dimensions), assigned indexes on each to all nations, and linked the dimensions with demographic, geographic, economic, and political aspects of a society (Kale \& Barnes, 1992), a feature unmatched by other frameworks. In addition, this framework is useful in formulating hypotheses for comparative cross-cultural studies. Consequently, Hofstede's operationalization of cultures (1980) is the norm used in international marketing studies (Dawar, Parker, \& Price, 1996; Sivakumar \& Nakata, 2001).

However, academic consideration dedicated to developing a better understanding of sport sponsorship, as part of international marketing, has yet to be conducted (Amis \& Cornwell, 2005; Santomier, 2008; Yoshida \& Heere, 2015). Furthermore, sponsorship can vary across geographic regions in that there are the "moderating effects of country" (Wang, Cheng, Purwanto, \& Erimutri, 2011, p. 5), which convey that a sports team's fans are not all similar in the way they view sport sponsorships. Also, for firms to be successful in the global marketplace they need to grasp the distinction between countries and cultures in order to construct appropriate marketing strategies 
based on these distinctions (Craig \& Douglas, 2001; Geng, Burton, \& Blakemore, 2002).

\subsection{Attitude toward the Sponsor}

Attitude is defined as "a learned predisposition to respond in a consistently favorable manner with respect to a given object" (Fishbein \& Ajzen, 1975, p. 6). The development of favorable attitudes toward a sponsor is a pivotal factor for sponsorship effectiveness (e.g., Alexandris, Tsaousi, \& James, 2007), and, as such, are expected to point to positive behavioral intentions (Laczniak, DeCarlo, \& Ramaswami, 2001). Thus, a sponsorship can change consumers' responses towards a specific sponsor, resulting in the development of positive attitudes towards the sponsor, which can then lead to increased consumer willingness to buy the sponsor's products (Swanson, Gwinner, Larson, \& Janda, 2003).

Nevertheless, little is known about how sponsorship outcomes, and implicitly attitudes toward sponsors, work in a cross-national setting (Yoshida \& Heere, 2015). The attitudes toward various sponsor categories may vary across countries, and in particular, as they pertain to jersey sponsorship. Although jersey sponsorship has been supported by many professional team sports and fans in Europe and internationally, this practice is relatively new in the U.S. and has been met by public opposition (Jensen, Bowman, Larson, \& Wang, 2013). In North America, some fans consider jersey sponsorship on game uniforms an "untouchable territory" that should remain free from financial exploitation (Lukas, 2009). Therefore, fans from the U.S. might have a negative attitude toward a jersey sponsor compared to Indian and British fans, as the U.S. has a short-term orientation cultural dimension, which means that although people from the U.S. have a respect for [sports] traditions (Hofstede et al., 2010), they prefer the status quo, which is to not have a sponsor on a team's jersey (Lukas, 2009). Following the previous propositions from past research, it is hypothesized that:

$\mathrm{H}_{1}$ : Attitude toward the sponsor will have a direct positive effect on purchase intentions.

$\mathrm{H}_{2}$ : Attitude toward the sponsor will have a direct positive effect on actual purchases.

$\mathrm{H}_{3}$ : The short-term orientation cultural dimension will have a direct positive effect on attitude toward the sponsor.

\subsection{Gratitude}

Algoe, Gable, \& Maisel (2010) defined gratitude as an emotional appreciation response for costly, yet intentionally provided, benefits from another individual. There is a limited amount of research in which scholars have examined the nature and role of gratitude within a sponsorship context (Kim, Kwak, \& Bunds, 2012); however, the significant role of gratitude in a consumer behavior context has been emphasized in previous research (Palmatier et al., 2009). Further, while there appears to be general accord among sponsorship researchers that a distinctive aspect of sponsorship that differentiates it from traditional advertising is consumer gratitude (Meenaghan, 2001), few researchers have empirically analyzed the impact of gratitude on sponsorship effectiveness (Kim et al., 2015). Kim and colleagues (2010) found that feelings of gratitude significantly predicted consumers' intent to purchase the sport benefactor's products in the U.S. Considering that purchase intentions are, in effect, favorable intentions toward actually purchasing a product or service (e.g., Dees, Bennett, $\&$ Ferreira, 2010), then gratitude can be considered predictive of consumers' actual behavior.

However, it is likely that the results of Kim and colleagues' (2010) study were impacted by the study's setting-the U.S. as trust, which is linked to gratitude (Palmatier et al., 2009), has been found to be influenced by national culture (e.g., Schumann et al., 2010). In addition, an implication derived from the academic literature is that there is a strong positive relationship between trust and collectivism, and a negative relationship between trust and individualism (e.g., Huff \& Kelley, 2005). Therefore, gratitude toward a sponsor may be enhanced among citizens in collectivist countries (i.e., India) compared to citizens in individualist countries (i.e., the U.S., the U.K.). It would seem that collectivists, who appear to place more importance on relationships and nurture them with more care than individualists, would have higher levels of trust than individualists (Huff \& Kelley, 2005), and hence, higher levels of gratitude. Furthermore, in collectivist societies, it is reasonable to expect that people think of themselves as members of a larger group (which could include sponsors), and expect members of the group to look after one another based on shared trust (Gwinner, 2005). In exchange for this support, one can feel absolute gratitude is owed to another (Hofstede et al., 2010). Thus, the researchers posit:

$\mathrm{H}_{4}$ : Gratitude will have a direct positive effect on purchase intentions.

$\mathrm{H}_{5}$ : Gratitude will have a direct positive effect on actual purchases.

$\mathrm{H}_{6}$ : The individualism cultural dimension will have a direct negative effect on gratitude. 


\subsection{Purchase Intentions and Actual Purchase Behaviors}

According to Spears \& Singh (2004), purchase intentions refer to the person's conscious plan in exerting an effort to purchase a brand. From a sponsor's perspective, a consumer's purchase intentions are the most useful indicator of sponsorship effectiveness, given their expected impact on future sales (Choi, Tsuji, Hutchinson, \& Bouchet, 2011). Moreover, the use of intentions to predict purchases depends on the notion that intentions are, in fact, good indicators of consumers' actual purchase behavior (Dees et al., 2010). However, the true long-term impact of a sponsorship on sales, or intent-to-purchase, is difficult to evaluate and, thus, often questioned (Biscaia et al., 2013; Gwinner \& Bennett, 2008; Mazodier \& Merunka, 2012; O’Reilly, Lyberger, McCarthy, Seguin, \& Nadeau, 2008). With few exceptions (i.e., Hickman, 2015; Yoshida et al., 2015), there is a lack of empirical sport data to support the intention-purchase connection, particularly in a sport sponsorship context.

Additionally, considering the influence of culture on an individual's personality, which in turn modifies consumer behavior (Samli, 1994), and bearing in mind that most aspects of consumer behavior are culture-bound (Hofstede et al., 2010), cultural influence may differentially impact actual purchases in different geographic areas. In past research, scholars have asserted that converging technology and disappearing income differences across countries will not lead to standardization of consumer behavior (De Mooij, 2004; De Mooij \& Hofstede, 2002).

Furthermore, greater pressure to conform to groups norms that prevail in collectivist countries (e.g., India) can affect consumer behavior, while members of individualist cultures (e.g., the U.S., the U.K.) are less likely to be pressured to buy brands that are not meaningful to them as an individual (e.g., Foscht, Maloles, Swoboda, Morschett, \& Sinha, 2008). So, since sponsors can be considered members of a group (Gwinner, 2005), and there is a greater pressure to agree with group norms when it comes to consumer behavior in collectivist cultures (Foscht et al., 2008), Indian sport fans presumably would have higher potential for actual purchase behavior of a sponsor's product(s) compared to American and British sport fans. Thus, the researchers posit:

$\mathrm{H}_{7}$ : Purchase intentions will have a direct positive effect on actual purchases.

$\mathrm{H}_{8}$ : The individualism cultural dimension will have a direct negative effect on actual purchases.

Based on the hypotheses generated from the literature review, the proposed model guiding this research is presented in Figure 1.

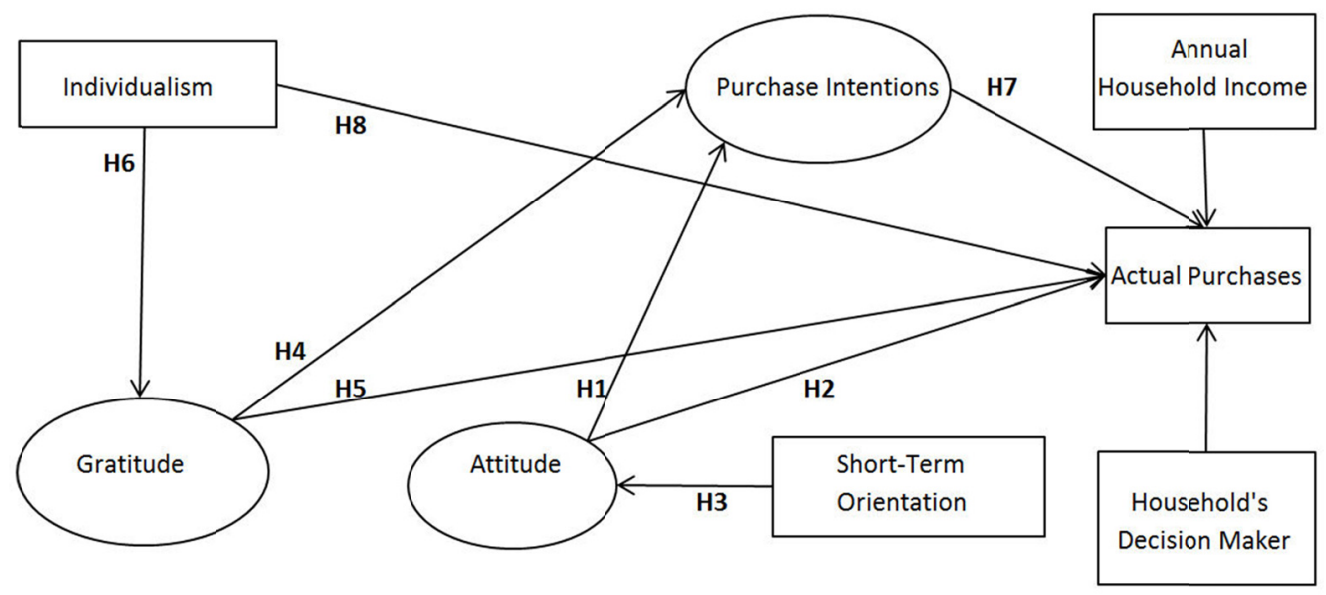

Figure 1. Hypothesized model

\section{Method}

To measure sponsorship outcomes and effectiveness, a survey was utilized, through which participants rated the effectiveness of EPL team Chelsea Football Club's (CFC) jersey sponsorship. The jersey sponsor for this study was Samsung, a multinational company that sells durable products such as computers, televisions, mobile phones, printers and refrigerators, and is regarded as one of the largest information technology companies in the world (Grobart, 2013). The researchers selected CFC, playing in the EPL, as this club is one of the largest global brands in a sport with an increasing global appeal (Karon, 2004).

The countries incorporated in the sample (U.K., U.S., and India) represented a range of cultural diversity, 
illustrated by the variety of index values for the cultural dimensions from Hofstede and colleagues' indexes (i.e., scales from 0 for the most collectivist and short-term orientation country to 100 for the most individualist and long-term orientation one; Hofstede et al., 2010). For example, individualism/collectivism varies from a high of 91 in the U.S., 89 in the U.K., to a low of 48 in India, while short-term/long-term orientation ranges from 51 in India and the U.K., to 26 in the U.S. (Hofstede et al., 2010).

\subsection{Participants and Data Collection}

Web-based questionnaires were utilized for the collection of data. The online survey was conducted in English, due to it being the most commonly used language in the selected countries. Only English-speaking countries were selected, as past researchers have argued that language and translation continue to present one of the biggest obstacles in cross-national research (Apentiik \& Parpart, 2006). When a different language is used across cultures, equivalence of the survey instrument is more likely to be absent, thus preventing meaningful cross-cultural comparisons (Tourangeau, Rips, \& Rasinski, 2000). Moreover, while translated materials encourage participation of non-English speakers, a set of items used to measure a construct in English might not accurately assess the underlying construct in a different language or culture (e.g., Harzing, 2006).

The survey link was advertised to administrators of CFC's official supporter clubs, which were identified from the official CFC website, and were located in the U.S., the U.K., and India. The survey link was also posted on CFC's official supporter clubs' Facebook pages, Twitter accounts, and forums of these three countries. The bulk of the study's sample was gathered from emailing administrators of CFC's official supporter clubs. These administrators, in turn, emailed the members of those supporter clubs. Moreover, it is worth noting that every CFC fan from the official supporter clubs needs to pay membership dues annually, otherwise the fans will be removed from those supporter clubs, and implicitly from the mailing lists.

The data collection procedure consisted of two phases. In Phase 1, a survey was conducted to examine attitude toward the sponsor, gratitude, and purchase intentions. Phase 2 involved a follow-up survey at a later date, using the sample from Phase 1 to collect data regarding actual purchases of CFC's jersey sponsor's products during the time between Phase 1 and Phase 2. Responses by individual participants during Phases 1 and 2 were matched using email addresses. The Phase 1 survey was conducted over 78 weeks, during which time a total of 588 questionnaires were returned. The researchers removed 79 questionnaires completed by CFC fans from countries other than the U.S., the U.K., and India, as indicated from the demographic portion of the survey regarding the CFC fans' country of residence.

Questionnaires with incorrect information and a missing e-mail address $(n=112)$ were also eliminated, leaving 397 usable surveys. The Phase 2 questionnaire was sent directly to the 397 Phase 1 participants to capture actual purchase behavior data. In the second phase, 252 questionnaires were returned. After deleting the outliers (i.e., statistical observations that are markedly different in value from the others of the sample), information from 231 respondents were used in the final analysis, with data collected from American ( $n=116$, which is $50.22 \%$ of the overall sample), British ( $n=45$, which is $19.48 \%$ of the overall sample) and Indian ( $n=70$, which comprises $30.30 \%$ of the overall sample) CFC fans. The profile of the respondents is shown in Table 1.

Table 1. Demopgraphic characteristics of respondents

\begin{tabular}{lr} 
Demographic variable & \\
\hline Gender & \\
Male (\%) & 89.60 \\
Female (\%) & 10.40 \\
Age & \\
18-34 (\%) & 69.30 \\
$35-54(\%)$ & 23.80 \\
55 and over (\%) & 6.90 \\
Education & 23.80 \\
$\quad$ High School or Some College (\%) & 53.70 \\
Undergraduate Degree (\%) & 22.50 \\
$\quad$ Graduate Degree (\%) & \\
Annual Household Income & 29.00 \\
Less than \$20,000 (\%) & 31.20 \\
\$20,000-\$59,999 (\%) & 17.70 \\
\$60,000-\$89,999 (\%) & 22.10 \\
\$90,000 or more (\%) & \\
Household's Decision Maker & 65.80 \\
$\quad$ No (\%) & 34.20 \\
$\quad$ Yes (\%) & \\
\hline
\end{tabular}


The threat of non-response bias (Dillman, Smyth, \& Christian, 2014; Jordan, Walker, Kent, \& Inoue, 2011) was addressed by comparing demographic information (i.e., age, education, income, and gender) of the Phase 2 non-respondents with the demographic characteristics of the respondents that completed the questionnaire in Phase 2. Based on the results of these comparisons, the authors concluded there were no major differences between the Phase 1 sample and the Phase 2 sample. A comparison on variables that were measured was also made between early and late respondents in Phase 2 (i.e., first thirty respondents and last thirty respondents), as late respondents have been shown to be an appropriate proxy for non-respondents (Dooley \& Lindner, 2003). No significant differences between early and late survey respondents were found.

\subsection{Measures}

The online survey included items adapted from previously validated instruments to measure three constructs: attitude toward the sponsor (Gwinner \& Bennett, 2008), gratitude (Palmatier et al., 2009), and purchase intentions (Gwinner \& Bennett, 2008; Hong, 2011). Slight modifications were made to suit the specific needs of this study. The items were presented in the same order for all three countries and contained identical designs. Actual purchase behaviors were collected using continuous numeric data (e.g., How many <sponsor name> products did you buy during the period between the first survey and today?), and $40.26 \%$ of the respondents acknowledged that they bought at least one sponsor's product. The researchers also employed two demographic items as control variables: annual household income $(1=$ less than $\$ 20,000 ; 2=\$ 20,000-\$ 59,999 ; 3=\$ 60,000$ - $\$ 89,999 ; 4=\$ 90,000$ or more $)$ and household's decision maker $(0=n o$, I am not the primary decision maker in my family with regard to making purchases; 1 = yes, I am the primary decision maker in my family with regard to making purchases). Descriptive statistics for these demographics appear in Table 1 and Table 3.

Each of the three nations was assigned a national culture index score according to Hofstede's typology of cultural dimensions used in this study (i.e., scales from 0 to 100 for individualism/collectivism and for short-term/long-term orientation; Hofstede et al., 2010). Also, Hui \& Triandis (1989), and Clarke III (2001) recommended scales with more response categories (i.e., scale points) as appropriate for cross-national research; thus, for this study the researchers used a 10-point Likert-type scale, anchored by "Strongly Disagree" (1) and "Strongly Agree" (10). Another reason for implementing a Likert-type scale with 10 points is that previous researchers have found strong differences in response styles between countries (e.g., Harzing, 2006). In particular, East Asian respondents have been shown to display a higher proportion of middle responses in comparison to U.S. and Canadian respondents who displayed more extreme response styles (e.g., Takahashi, Ohara, Antonucci, \& Aakiyama, 2002). Dolnicar \& Grün (2007) confirmed that this difference was also apparent between Australian and Asian respondents when scales with explicit mid-points are used. Similarly, Johnson, Kulesa, Cho, \& Shavitt (2005), and Harzing (2006) suggested that national-level collectivism might be related to middle responses styles. This tendency is reinforced by the fact that most collectivist countries are characterized by an indirect communication style, where the expression of strong opinions is avoided (Hall, 1976). Therefore, researchers need to pay more attention to response styles in their data collection procedures as research clearly shows that there is stability in response style differences between countries (Harzing, 2006).

Finally, the attentiveness of survey participants was tested by inserting the statement "On this question please click on "Strongly Agree" so we can ensure you are paying attention" among the sponsorship outcomes' items to account for measurement error, which is a possible survey error that needs to be minimized to improve survey estimates (Dillman et al., 2014).

\subsection{Data Analysis}

Data were analyzed using SPSS 21 and AMOS 21. Before any analyses were conducted, the normality of the data was assessed. Then, to assess the measurement model, a confirmatory factor analysis (CFA) was conducted. Internal consistency of the constructs was measured through composite reliability (CR; Hair, Black, Babin, \& Anderson, 2009). Evidence of convergent validity was evaluated through assessment of the average variance extracted (AVE) scores, while evidence of discriminant validity was established when the AVE score for each construct exceeded the squared correlations between that and any other construct (Fornell \& Larcker, 1981).

The researchers utilized structural equation modeling (SEM; Byrne, 2010) to test the hypothesized relationships. Goodness of fit for the measurement and structural models was assessed with the ratio of chi-square $\left(\chi^{2}\right)$ to its degrees of freedom, Tucker-Lewis Index (TLI), comparative-of-fit-index (CFI), goodness-of-fit index (GFI), root mean square error of approximation (RMSEA), and standardized root mean residual (SRMR). Sample sizes of 200 or more have been considered acceptable for use of SEM (Garver \& Mentzer, 1999; Hoelter, 1983), thus the current sample was deemed suitable. 


\section{Results}

The data were screened before being analyzed, where the level of normality in the dataset was assessed based on the coefficients of skewness and kurtosis for all variables. An examination of the univariate statistics produced one value which was greater than 10 for univariate kurtosis, which indicated the level of normality in the dataset was problematic (Hair et al., 2009). The researchers removed nine cases based on univariate outlier detection; the subsequent skewness and kurtosis values were determined to be normal. Multivariate outliers were identified with the use of Mahalanobis $D^{2}$ measure. Hair et al. (2009) recommend a conservative threshold of $p<.001$ for the multivariate outlier test. Twelve cases were removed based on multivariate outlier detection, where both $p$-values of the Mahalanobis $D^{2}$ equaled 000 .

\subsection{Measurement Model}

Examining the results of the CFA, the researchers noted the standardized factor loadings ranged from .61 to .98 , surpassing the suggested cut-off point of .50 (Hair et al., 2009), and were all significant $(p<.001)$. As shown in Table 2, all the composite reliability (CR) values ranged from .86 to .97 , indicating acceptable levels of reliability for the constructs according to the recommended .70 threshold (Hair et al., 2009). All average variance extracted (AVE) values were greater than the .50 standard for convergent validity (Fornell \& Larcker, 1981), ranging from .62 to .91 , providing evidence of acceptable levels of convergent validity for the constructs. In addition, evidence of discriminant validity was found given that the AVE value for each construct is greater than the squared correlation between the construct and other constructs in the model (Fornell \& Larcker, 1981). Additional descriptive statistics (i.e., mean and standard deviations) and the correlation matrix are listed in Table 3 , with the correlations among constructs and the square root of the AVE values included on the diagonal. The three diagonal elements of the latent variables were all larger than their corresponding correlation coefficients, evidence of appropriate discriminant validity.

Table 2. Factor loadings, Composite Reliability (CR), and Average Variance Extracted (AVE)

\begin{tabular}{|c|c|c|c|}
\hline Constructs/items & Loading $^{0}$ & CR & AVE \\
\hline Atittude Toward the Sponsor ${ }^{\mathrm{a}}$ & & .97 & .91 \\
\hline I like $<$ sponsor name $>$ brand & .962 & & \\
\hline$<$ Sponsor name $>$ is a very good brand of $<$ product-category $>$ & .928 & & \\
\hline I have a favorable disposition/mood toward < sponsor name $>$ & .972 & & \\
\hline Gratitude $^{a}$ & & .95 & .86 \\
\hline I feel grateful to $<$ sponsor name $>$ for its sponsorship to $<$ team name $>$ & .963 & & \\
\hline I feel thankful to $<$ sponsor name $>$ for its sponsorship to $<$ team name $>$ & .976 & & \\
\hline 1 appreciate < sponsor name $>$ & .833 & & \\
\hline Purchase Intentions ${ }^{a}$ & & .86 & .62 \\
\hline I will buy a <product-category $>$ made by $<$ sponsor name $>$ & .829 & & \\
\hline Next time I need to buy a < product-category >, I would consider buying < sponsor name $>$ & .874 & & \\
\hline I will be more likely to buy a $<$ product-category $>$ made by $<$ sponsor name $>$ over its competitors & .794 & & \\
\hline $\begin{array}{l}\text { The <sponsor name }>\text { sponsorship to <team name }>\text { makes me more likely to buy } \\
\text { a }<\text { product-category }>\text { made by }<\text { sponsor name }>\end{array}$ & .614 & & \\
\hline
\end{tabular}

Table 3. Mean (M), Standard Deviation (SD), and Correlation Matrix

\begin{tabular}{|c|c|c|c|c|c|c|c|c|c|c|}
\hline & & & \multicolumn{8}{|c|}{ Correlation Matrix } \\
\hline Variables & $\mathrm{M}$ & SD & 1 & 2 & 3 & 4 & 5 & 6 & 7 & 8 \\
\hline 1. Attitude Toward the Sponsor & 8.34 & 1.63 & .95 & & & & & & & \\
\hline 2. Gratitude & 7.22 & 2.21 & .55 & .93 & & & & & & \\
\hline 3. Purchase Intentions & 7.70 & 2.09 & .72 & .50 & .78 & & & & & \\
\hline 4. Actual Purchases & .61 & .88 & .20 & .17 & .24 & & & & & \\
\hline 5. Individualism/Collectivism & 77.58 & 19.56 & .01 & -.13 & -.01 & -.08 & & & & \\
\hline 6. Short-Term/Long-Term Orientation & 38.45 & 12.53 & -.09 & -.06 & -.06 & .03 & -.69 & & & \\
\hline 7. Annual Household Income & 2.33 & 1.12 & .06 & -.06 & .02 & .02 & .48 & -.36 & & \\
\hline 8. Household's Decision Maker & .34 & .48 & -.01 & -.12 & -.01 & -.02 & .28 & -.23 & .15 & \\
\hline
\end{tabular}

Note. Diagonals in bold are square root of AVE. 
In accordance with the aim of this study, the results of the measurement model $\left[\chi^{2}(84)=227.878, p<.001\right.$, $\left.\chi^{2} / \mathrm{df}=2.713, \mathrm{TLI}=.93, \mathrm{CFI}=.94, \mathrm{GFI}=.89, \mathrm{RMSEA}=.086, \mathrm{SRMR}=.001\right]$ led the researchers to conclude there was acceptable fit to the data. Although the chi-square goodness of fit index was statistically significant, in general, chi-square-based statistics can be misleading (Schumacker \& Lomax, 2010). Also, the ratio of the chi-square to its degrees of freedom was within the 3.0 criteria (Kline, 2011). The values for the additional fit indices were close to, or exceeded the critical values for good model fit, as CFI, TLI and GFI values higher than .90 are considered to have a close fit (Hair et al., 2009). However, TLI and GFI values are sensitive to sample size and, therefore, researchers need to be cautious with interpretation when assessing model fit (Hu \& Bentler, 1999). The observed RMSEA value was slightly over this estimate, as Hu \& Bentler (1999) suggested RMSEA values between .05 and .08 to indicate a fair fit, but scholars have cautioned about using precise cutoff points for RMSEA (Chen, Curran, Bollen, Kirby, \& Paxton, 2008; Marsh, Hau, \& Wen, 2004). Moreover, the SRMR value is preferred over the RMSEA value (e.g., Iacobucci, 2010). Any SRMR value from .05 to .10 is considered indicative of an acceptable fit, while a SRMR value below .05 indicates an excellent fit (Hu \& Bentler, 1999); as such, the observed values were considered to be acceptable.

\subsection{Structural Model}

The examination of the structural model included a test of the overall model fit, as well as individual tests of the relationships among constructs. The overall assessment of the structural model indicated an acceptable fit to the data $\left[\chi^{2}(12)=25.918, p=.011, \chi^{2} / \mathrm{df}=2.160, \mathrm{TLI}=.93, \mathrm{CFI}=.97, \mathrm{GFI}=.97, \mathrm{RMSEA}=.071, \mathrm{SRMR}=.059\right]$. Figure 2 shows the standardized regression coefficients of the structural model. Attitude toward the sponsor showed a positive effect, and a significant relationship with purchase intentions $(\beta=.63, p<.001)$, but no significant relationship was observed with actual purchases $\left(\beta_{=} .04, p=.669\right)$. Thus, $\mathrm{H}_{1}$ was supported, but $\mathrm{H}_{2}$ was not.

The short-term/long-term orientation cultural dimension showed a negative effect, but was not significant in its relationship with attitude toward the sponsor $(\beta=-.01, p=.833)$; therefore, $\mathrm{H}_{3}$ was not supported. Additionally, gratitude had a significant, positive effect on purchase intentions $(\beta=.15, p=.005)$, but was not significant in relation to actual purchases $(\beta=.05, p=.554)$, which did provide support for $\mathrm{H}_{4}$, but not $\mathrm{H}_{5}$. The individualism/collectivism cultural dimension had a significant, negative effect on gratitude $(\beta=-.13, p=.031)$, so $\mathrm{H}_{6}$ was supported.

There was a significant, positive path from purchase intentions to actual purchases $(\beta=.18, p=.049)$, when controlling for the annual household income and the household's decision maker; thus, $\mathrm{H}_{7}$ was also supported. The path between the individualism/collectivism cultural dimension and actual purchases was negative, but not significant $(\beta=-.11, p=.150$ ), when controlling for the annual household income and the household's decision maker, which did not support $\mathrm{H}_{8}$.

Jointly, attitude toward the sponsor, gratitude, the short-term/long-term orientation and the individualism/collectivism cultural dimensions accounted for $53 \%$ of the variance of purchase intentions $\left(R^{2}\right.$ $=.53$ ). Attitude toward the sponsor, gratitude, the short-term/long-term orientation and the individualism/collectivism cultural dimensions, and purchase intentions accounted for $7 \%$ of the variance of actual purchases $\left(R^{2}=.07\right)$, when controlling for the annual household income and the household's decision maker. These two control variables were regressed onto the endogenous variable of actual purchases; however, their individual effect was not found to be significant $(\beta=.07, p=.349$; respectively, $\beta=.01, p=.914$ ).

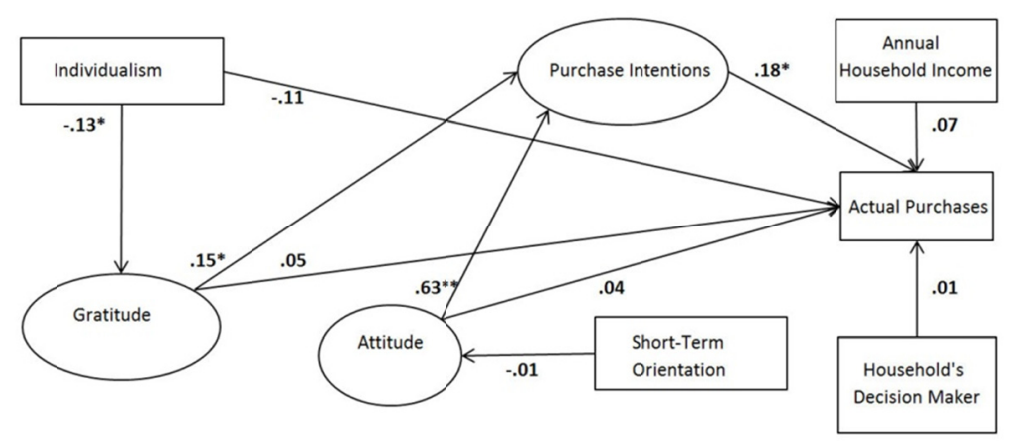

Figure 2. Standardized estimates of the structural model

Note. $* * \mathrm{p} \leq .001, * \mathrm{p}<.05$. 


\section{Discussion and Implications}

There is a growing interest in determining how sponsorship outcomes such as attitude toward a sponsor, gratitude, and purchase intentions function in relation to actual purchase behaviors at a cross-national level (Amis \& Cornwell, 2005; Yoshida \& Heere, 2015); yet few researchers have pursued such an investigation, highlighting the significance of this inquiry. Scholars have previously theorized upon the likelihood that consumer behavior might be culture-bound (e.g., Hofstede et al., 2010; Yoshida \& Heere, 2015); in the present study the researchers have empirically-tested these assumptions in the context of sport sponsorship. The results suggest that gratitude in sponsorship may be responsive to the individualism/collectivism cultural dimension. Furthermore, a positive link between intentions and actual purchase behaviors has often been suggested (e.g., Dees et al., 2010), but there has been a lack of empirical work providing analysis of actual behaviors to support such an assertion. In the present study, the researchers added actual purchase behavior to assess whether there was a significant correlation between intentions and actual purchase behaviors at a cross-national level.

The link between attitude toward the sponsor and purchase intentions was significant, consistent with findings reported in prior sponsorship research (e.g., Alexandris et al., 2012; Biscaia et al., 2013); scholars have proposed that the development of positive attitudes towards a sponsor leads to increased consumer willingness to buy the sponsor's products. The attitude toward the sponsor variable, however, was not a significant predictor of actual purchases for the jersey sponsor's products in this study. There was no consistency between attitude and behavior in this study, which is contrary to the Theory of Planned Behavior, which includes the premise that actual behavior is influenced by an individual's attitude (Ajzen, 1985). This may indicate that, although international fans do have the intent to purchase the sponsor's products, they did not acquire the sponsor's products based on their positive and strong attitudes toward the sponsor (see Table 3 and Figure 2). It could be the case that, at a global level, positive attitudes toward the sponsor will normally lead to intentions to purchase, but there can be a complex transition from attitudes to action which will necessitate additional variables and increasing specificity in the measures of attitudes and behaviors (Funk, Haugtvedt, \& Howard, 2000). Also, as Christensen (2006), and Tsiotsou \& Alexandris (2009) noted, sponsorship evaluation research is still at early stages, due to lack of established theoretical frameworks that can explain a consumer's decision making process. This aspect certainly warrants further investigation.

In addition, the short-term/long-term orientation cultural dimension was not a significant predictor of the attitude toward the sponsor, contrary to what was proposed with $\mathrm{H}_{3}$. When it comes to possibly not respecting [sports] traditions, it can be argued that the surveyed fans are not concerned if their favorite team has a jersey sponsor. This can be particularly true in the U.S. for jersey sponsorship, where some professional sport leagues (i.e., Major League Baseball, the National Basketball Association, the National Football League, and the National Hockey League) have yet to implement game-day jersey sponsorships. Therefore, as levels of the orientation cultural dimension decrease, attitude toward the sponsor's levels may not necessarily decrease. Moreover, making a case for a potentially successful implementation of jersey sponsorship in the U.S., the favorable opinions/attitudes fans have for a global company may be further enhanced if the affiliations between jersey sponsors and sport teams result in lower ticket prices, reduce team expenses, or assist in attracting/retaining star players (Jensen, Bowman, Wang, \& Larson, 2012). Thus, there can be unique circumstances related to sport that international corporations should be aware of when they attempt to build more effective cross-national sponsorship initiatives.

In line with this study's findings on attitude toward the sponsor, gratitude was a significant predictor of purchase intentions, but not of actual purchase behaviors. This finding is contrary to prior speculation, in which scholars have stated that gratitude may lead to actual behavior (e.g., Kim et al., 2010; Palmatier et al., 2009). Expecting that feelings of gratitude generate an ingrained sense of psychological pressure to return the benefit received (Dahl, Honea, \& Manchanda, 2005), it appears that fans' gratitude did not reciprocate through actual purchases of the team sponsor's products. Additionally, considering that the individualism/collectivism cultural dimension in this study had a significant negative effect on gratitude, it can be acknowledged for the first time that as there is movement to the individualistic end of the cultural dimension, gratitude levels will decrease. In this study the findings provide evidence that the collectivist fans (i.e., Indian fans) have more appreciation for the team's sponsor than the individualist fans (i.e., the British and American fans).

One possible way to increase gratitude levels of fans from individualistic countries could be through corporate social responsibility (CSR) strategies that include social objectives within sponsorship initiatives (Alexandris et al., 2012; Cunningham, Cornwell, \& Coote, 2009), as the more consumers perceive an organization as socially responsible, the more they will trust products sold by that organization (Ko, Rhee, Kim, \& Kim, 2014). CSR activities could inspire consumers' trust and, thus, higher levels of gratitude. Also, the importance of trust as a 
building block of relationships is even greater in the sport context, since support from fans for players, coaches, and teams is basically based on the created relationships (Lee, Bang, \& Lee, 2013).

The Theory of Planned Behavior (Ajzen, 1985), one of the most widely applied theories in consumer research (e.g., Manning, 2009), includes the premise that a link can be present between purchase intentions and behavior, as "at its core, the Theory of Planned Behavior is concerned with the prediction of intentions" (Ajzen, 2011, p. 1115). The results from the current study provide evidence that purchase intentions is a predictor of actual purchases for the jersey sponsor's products, in contrast to Hickman's (2015) and Yoshida and colleagues' (2015) research on intentions and actual sport behaviors in the U.S., and, respectively, Japan. Furthermore, sponsorship should account for behavioral change in order to be proven effective (Amis \& Cornwell, 2005), and the most desirable behavioral change from a sponsor's perspective is the influence on sales (Choi et al., 2011; Kim et al., 2015); thus, this research fills a gap regarding the examination of actual behaviors. However, the observed sponsorship outcomes accounted for only a small percent of variance in predicting behavior (i.e., 7 \%); therefore, future research should take into account more (sponsorship) variables when studying behavior. Also taking into consideration past results, it appears that the link between intentions and actual purchases is a complex one that will require further research to more fully understand.

The link between the individualism/collectivism cultural dimension and actual purchase behaviors was not significant in this study, dissimilar to what was assumed as a greater pressure to conform with group norms when it comes to consumer behavior in collectivist cultures (e.g., Foscht et al., 2008). Sport has become a global phenomenon because of its capacity to attract people of different nationalities (Ratten, 2011). To exemplify, the declining birth rate and the aging U.S. population, and the large increase in middle class households in India together with its large population, have enticed more professional sport teams to India (Ratten \& Ratten, 2011). Lately, the use across the globe of multiple new media/digital platforms (i.e., the convergence of telecommunications, computing and traditional media, such as social media, video and audio streaming, internet protocol television, online video gaming, etc.) in sports sponsorship communications, enables brands to employ multiple media channels and publicity methods in order to sell products (McAllister \& Turow, 2002; Santomier, 2008). Consequently, sport consumers have a strong desire to be global citizens and this desire is manifested by their purchases of global brands' products (Kim \& Heere, 2012).

Finally, the household production theory of Becker (1965) includes the premise that expenditure rises with income. Therefore, household income can have a positive influence on expenditures (Thibaut, Vos, \& Scheerder, 2014). Moreover, people belonging to low-income groups are more inclined to be influenced by family members because, for example, they are financially dependent on the household's decision maker (Yousaf \& Huaibin, 2013). For instance, a respondent will provide his or her own intention to purchase the product, but the decision maker in the respondent's household may play a role in the final purchase decision (Morwitz, Steckel, \& Gupta, 2007). However, this study's control variables (i.e., annual household income and household's decision maker) were not found to be predictors of actual behavior. These findings can be possibly explained by the fact that consumers may be better able to predict their own future behavior about buying durable goods (e.g., electronics which this study's jersey sponsor is selling), as purchase decisions for durable goods are seen as more important to the consumer than purchase decisions for non-durable goods (e.g., food; Morwitz et al., 2007). Therefore, consumers may deliberate considerably about the purchase decision for durable goods as respondents might have reflected on all of the aspects of the purchase situation, not just their household income and decision maker. Moreover, these two respondents' demographics that might have influenced the analyzed sponsorship outcomes were controlled in the current analysis and were found not significant, further strengthening the validity of the outcomes' correlations.

To summarize, research analyzing multi-country effects of sponsorship is almost non-existent (Amis \& Cornwell, 2005; Yoshida \& Heere, 2015); therefore, highlighting the importance of this paper for the field, which thus far has included few studies which have advanced our understanding of how cultural differences among continents might affect the sport marketing strategies of international firms (Yoshida \& Heere, 2015). It seems that some sponsorship variables (e.g., gratitude) can be influenced by Hofstede's cultural dimensions; therefore, sport research developed in one country should be assessed in other countries as well. Given these results and their broad implications, further investigation on the way countries influence the relationships among key variables in sponsorship contexts is warranted.

\section{Limitations and Future Research}

The authors of this study tested the application of sponsorship outcomes using just one team and sponsor. To test the validity and generalization of the research findings, future research will require a greater variety of 
sponsorship contexts, such as different sports, teams, cultural dimensions, product categories, purchase cycles (i.e., durable/non-durable goods), and sponsor levels. Also, the variation of approximately four to ten months in the number of days between collecting purchase intentions and actual purchases for the jersey sponsor's products (i.e., electronics) may not have been sufficient to be certain the actual purchase behaviors are accurate. However, literature from other academic fields suggest that it is not clear whether the strength of the intent-behavior relationship should increase or decrease with the length of time between the intent and behavior measurement (e.g., Morwitz et al., 2007). Second, while fans engaged in membership programs are often suggested to be highly identified with the team, the actual level of team identification for the CFC fans was not controlled in these research analyses; previous studies suggest that fans' link with the team tend to have a role on sponsorship outcomes (e.g., Alexandris et al., 2012). However, there were some cases where team identification didn't have a significant connection with actual behavior (e.g., Yoshida et al., 2015). Future studies could compare fans with different levels of team identification to better understand its role on sponsorship outcomes.

While this research was developed within three local contexts (i.e., U.S., U.K., and India), it might not be applicable to consumers in other countries. Thus, researchers should test these findings with more countries where sponsorship has experienced growth, such as China and Brazil. Fourth, the current study considered only five variables, and other variables may help to further explain sponsorship effectiveness. In future studies, researchers ought to test cross-national differences with other sponsorship effects, such as awareness, fit, word of mouth, goodwill, and image transfer. Furthermore, future attempts should be made to also include additional variables in global sponsorship models, as the results could have been significantly influenced, for example, by sponsorship activation in each market/country. However, many sports organizations market themselves globally, instead of focusing on one geographic region, as they can save time and money (e.g., Ratten, 2011). Fifth, the data for this research was collected with the use of a purposive sampling method, which can make research methods susceptible to bias. However, the sampling judgments made by the authors were based on clear and analytical criteria in an effort to reduce bias.

\section{Acknowledgements}

This work was supported by funds received from the NASSM Research Grant Program.

\section{References}

Ajzen, I. (1985). From intentions to actions: A theory of planned behavior. In J. Kuhl \& J. Beckman (Eds.), Action-control: From cognition to behavior (pp. 11-39). Heidelberg, Germany: Springer. https://doi.org/10.1007/978-3-642-69746-3_2

Ajzen, I. (2011). The theory of planned behaviour: Reactions and reflections. Psychology \& Health, 26, 1113-1127. https://doi.org/10.1080/08870446.2011.613995

Alexandris, K., Tsaousi, E., \& James, J. D. (2007). Predicting sponsorship outcomes from attitudinal constructs: The case of a professional basketball event. Sport Marketing Quarterly, 16, 130-139.

Alexandris, K., Tsiotsou, R. H., \& James, J. D. (2012). Testing a hierarchy of effects model of sponsorship effectiveness. Journal of Sport Management, 26, 363-378. https://doi.org/10.1123/jsm.26.5.363

Algoe, S. B., Gable, S. L., \& Maisel, N. C. (2010). It's the little things: Everyday gratitude as a booster shot for $\begin{array}{lllll}\text { romantic } & \text { relationships. } & \text { Personal } & \text { Relationships, } & 17,\end{array}$ https://doi.org/10.1111/j.1475-6811.2010.01273.x

Amis, J. M., \& Cornwell, T. B. (2005). Global sport sponsorship. Oxford: Berg Publishers.

Apentiik, C. R. A., \& Parpart, J. L. (2006). Working in different cultures: Issues of race, ethnicity. In V. Desai, \& R. B. Potter (Eds.), Doing development research (pp. 34-43). London: Sage. https://doi.org/10.4135/9781849208925.n4

Armstrong, J. S. (1985). Long-range forecasting. New York: John Wiley.

Becker, G. S. (1965). A theory of the allocation of time. The Economic Journal, 75, 493-517. https://doi.org/10.2307/2228949

Biscaia, R., Correia, A. F., Rosado, A. F., Ross, S. D., \& Maroco, J. (2013). Sport sponsorship: The relationship between team loyalty, sponsorship awareness, attitude toward the sponsor and purchase intentions. Journal of Sport Management, 27, 288-302. https://doi.org/10.1123/jsm.27.4.288

Biscaia, R., Correia, A. F., Ross, S. D., \& Rosado, A. F. (2014). Sponsorship effectiveness in professional sport: An examination of recall and recognition among soccer fans. International Journal of Sports Marketing \& 
Sponsorship, 16(1), 7-23. https://doi.org/10.1108/IJSMS-16-01-2014-B002

Breuer, C., \& Rumpf, C. (2012). The viewer's reception and processing of sponsorship information in sport telecasts. Journal of Sport Management, 26, 521-531. https://doi.org/10.1123/jsm.26.6.521

Byrne, B. M. (2010). Structural equation modeling with AMOS: Basic concepts, applications, and programming. New York: Routledge.

Chen, F., Curran, P. J., Bollen, K. A., Kirby, J., \& Paxton, P. (2008). An empirical evaluation of the use of fixed cutoff points in RMSEA test statistic in structural equation models. Sociological Methods \& Research, 36, 462-494. https://doi.org/10.1177/0049124108314720

Choi, J., Tsuji, Y., Hutchinson, M., \& Bouchet, A. (2011). An investigation of sponsorship implications within a state sports festival: The case of the Florida Sunshine State Games. International Journal of Sports Marketing \& Sponsorship, 12, 108-123. https://doi.org/10.1108/IJSMS-12-02-2011-B003

Christensen, S. (2006). Measuring consumer reactions to sponsoring partnerships based upon emotional and attitudinal responses. International Journal of Market Research, 48(1), 61-80.

Clarke III, I. (2001). Extreme response style in cross-cultural research. International Marketing Review, 18, 301-324. https://doi.org/10.1108/02651330110396488

Craig, C. S., \& Douglas, S. P. (2005). International marketing research. London: John Wiley \& Sons.

Cunningham, S., Cornwell, T. B., \& Coote, L. V. (2009). Expressing identity and shaping image: The relationship between corporate mission and corporate sponsorship. Journal of Sport Management, 23(1), 65-86. https://doi.org/10.1123/jsm.23.1.65

Dahl, D. W., Honea, H., \& Manchanda, R. V. (2005). Three Rs of interpersonal consumer guilt: Relationship, reciprocity, reparation. Journal of Consumer Psychology, 15, 307-315. https://doi.org/10.1207/s15327663jcp1504_5

Dawar, N., Parker, P. M., \& Price, L. J. (1996). A cross-cultural study of interpersonal information exchange. Journal of International Business Studies, 27, 497-516. https://doi.org/10.1057/palgrave.jibs.8490142

De Mooij, M. (2004). Consumer behaviour and culture: Consequences for global marketing and advertising. Thousand Oaks, CA: Sage.

De Mooij, M., \& Hofstede, G. (2002). Convergence and divergence in consumer behavior: Implications for international retailing. Journal of Retailing, 78(1), 61-69. https://doi.org/10.1016/S0022-4359(01)00067-7

De Mooij, M., \& Hofstede, G. (2010). The Hofstede model: Applications to global branding and advertising strategy and research. International Journal of Advertising, 29(1), 85-110. https://doi.org/10.2501/S026504870920104X

Dees, W., Bennett, G., \& Ferreira, M. (2010). Personality fit in NASCAR: An evaluation of driver-sponsor congruence and its impact on sponsorship effectiveness outcomes. Sport Marketing Quarterly, 19(1), 25-35.

Dillman, D. A., Smyth, J. D., \& Christian, L. M. (2014). Internet, phone, mail, and mixed-mode surveys: The tailored design method. Hoboken, NJ: John Wiley \& Sons.

Dolnicar, S., \& Grün, B. (2007). How constrained a response: A comparison of binary, ordinal and metric answer formats. Journal of Retailing and Consumer Services, 14, 108-122. https://doi.org/10.1016/j.jretconser.2006.09.006

Dooley, L. M., \& Lindner, J. R. (2003). The handling of nonresponse error. Human Resource Development Quarterly, 14(1), 99-110. https://doi.org/10.1002/hrdq.1052

Fishbein, M., \& Ajzen, I. (1975). Belief, attitude, intention, and behavior: An introduction to theory and research. Reading, MA: Addison-Wesley.

Fornell, C., \& Larcker, D. F. (1981). Evaluating structural equation models with unobservable variables and measurement error. Journal of Marketing Research, 18(1), 39-50. https://doi.org/10.2307/3151312

Foscht, T., Maloles III, C., Swoboda, B., Morschett, D., \& Sinha, I. (2008). The impact of culture on brand perceptions: A six-nation study. Journal of Product \& Brand Management, 17, 131-142. https://doi.org/10.1108/10610420810875052

Funk, D. C., Haugtvedt, C. P., \& Howard, D. R. (2000). Contemporary attitude theory in sport: Theoretical considerations and implications. Sport Management Review, 3, 125-144. 
https://doi.org/10.1016/S1441-3523(00)70082-9

Funk, D. C., Mahony, D. F., \& Havitz, M. E. (2003). Sport consumer behavior: Assessment and direction. Sport Marketing Quarterly, 12, 200-205.

Garver, M. S., \& Mentzer, J. T. (1999). Logistics research methods: Employing structural equation modeling to test for construct validity. Journal of Business Logistics, 20(1), 33-57.

Geng, L., Burton, R., \& Blakemore, C. (2002). Sport sponsorship in China: Transition and evolution. Sport Marketing Quarterly, 11(1), 20-32.

Grobart, S. (2013). How Samsung became the world's no. 1 smartphone maker. Business Week. Retrieved from http://www.businessweek.com/articles/2013-03-28/how-samsung-became-the-worlds-no-dot-1-smartphonemaker

Gwinner, K. (2005). Image transfer in global sport sponsorship: Theoretical support and boundary conditions. In J. M. Amis \& T. B. Cornwell (Eds.), Global sport sponsorship (pp. 163-178). Oxford: Berg Publishers.

Gwinner, K., \& Bennett, G. (2008). The impact of brand cohesiveness and sport identification on brand fit in a sponsorship context. Journal of Sport Management, 22, 410-426. https://doi.org/10.1123/jsm.22.4.410

Hair, J. F., Jr., Black, W. C., Babin, B. J., \& Anderson, R. E. (2009). Multivariate data analysis. Upper Saddle River, NJ: Prentice Hall.

Hall, E. T. (1976). Beyond culture. New York: Doubleday.

Harzing, A. W. K. (2006). Response styles in cross-national survey research: A 26-country study. International Journal of Cross Cultural Management, 6, 243-266.

Hickman, T. M. (2015). The impact of fan identification, purchase intentions, and sponsorship awareness on sponsors' share of wallet. Sport Marketing Quarterly, 24, 170-182.

Hoelter, J. W. (1983). The analysis of covariance structures goodness-of-fit indices. Sociological Methods \& Research, 11, 325-344. https://doi.org/10.1177/0049124183011003003

Hofstede, G. (1980). Culture's consequences: International differences in work-related values. Beverly Hills, CA: Sage Publications.

Hofstede, G. (2001). Culture's consequences: Comparing values, behaviors, institutions, and organizations across nations. Thousand Oaks, CA: Sage.

Hofstede, G., Hofstede, G. J., \& Minkov, M. (2010). Cultures and organizations, software of the mind: Intercultural cooperation and its importance for survival. New York: McGraw-Hill Companies, Inc.

Hong, J. (2011). Sport fans' sponsorship evaluation based on their perceived relationship value with a sport property. International Journal of Sport Management and Marketing, 9, 116-131. https://doi.org/10.1504/IJSMM.2011.040260

Hu, L., \& Bentler, P. M. (1999). Cutoff criteria for fit indexes in covariance structure analysis: Coventional criteria versus new alternatives. Structural Equation Modeling, 6(1), 1-55. https://doi.org/10.1080/10705519909540118

Huff, L., \& Kelley, L. (2005). Is collectivism a liability? The impact of culture on organizational trust and customer orientation: A seven-nation study. Journal of Business Research, 58(1), 96-102. https://doi.org/10.1016/S0148-2963(02)00478-2

Hui, C. H., \& Triandis, H. C. (1989). Effects of culture and response format on extreme response style. Journal of Cross-Cultural Psychology, 20, 296-309. https://doi.org/10.1177/0022022189203004

Iacobucci, D. (2010). Structural equations modeling: Fit indices, sample size, and advanced topics. Journal of Consumer Psychology, 20, 90-98. https://doi.org/10.1016/j.jcps.2009.09.003

IEG. (2016). As sponsorship borders fall, spending rises. IEG Sponsorship Report. Retrieved from http://www.sponsorship.com/IEGSR/2016/01/05/As-Sponsorship-Borders-Fall,-Spending-Rises.aspx

Jensen, R. W., Bowman, N. D., Larson, B. V., \& Wang, Y. (2013). Looking at shirt sponsorships from both sides of the pond: Comparing global trends versus America's Major League Soccer. Soccer \& Society, 14, 515-524. https://doi.org/10.1080/14660970.2012.753532

Jensen, R. W., Bowman, N. D., Wang, Y., \& Larson, B. V. (2012). New league, new market and new sponsorship: An exploratory study of attitudes towards shirt sponsorship in Major League Soccer. Soccer \& Society, 13, 
536-554. https://doi.org/10.1080/14660970.2012.677227

Johnson, T. J., Kulesa, P., Cho, Y. I., \& Shavitt, S. (2005). The relation between culture and response styles. Journal of Cross-Cultural Psychology, 36, 264-277. https://doi.org/10.1177/0022022104272905

Jordan, J. S., Walker, M., Kent, A., \& Inoue, Y. (2011). The frequency of nonresponse analyses in the Journal of Sport Management. Journal of Sport Management, 25, 229-239. https://doi.org/10.1123/jsm.25.3.229

Kale, S. H., \& Barnes, J. W. (1992). Understanding the domain of cross-national buyer-seller interactions. Journal of International Business Studies, 23, 101-132. https://doi.org/10.1057/palgrave.jibs.8490261

Karon, T. (2004). What soccer means to the world. Time. Retrieved from http://www.time.com/time/arts/article/0,8599,671302,00.html

Kim, C., \& Heere, B. (2012). Consumers from emerging markets: Perceptions and attitudes toward global sporting brands. Sport Marketing Quarterly, 21(1), 19-31.

Kim, Y. K., Kwak, D. H., \& Bunds, K. S. (2012). Tapping into feelings of gratitude: A new approach in understanding how sponsorship works. Presented at the annual conference of North American Society for Sport Management, Seattle, WA.

Kim, Y. K., Lee, H. W., Magnusen, M. J., \& Kim, M. (2015). Factors influencing sponsorship effectiveness: A meta-analytic review and research synthesis. Journal of Sport Management, 29, 408-425. https://doi.org/10.1123/jsm.2014-0056

Kim, Y. K., Smith, R., \& James, J. D. (2010). The role of gratitude in sponsorship: The case of participant sports. International Journal of Sports Marketing \& Sponsorship, 12(1), 53-75. https://doi.org/10.1108/IJSMS-12-01-2010-B006

Kline, R. B. (2011). Principles and practice of structural equation modeling. New York: The Guilford Press.

Ko, Y. J., Rhee, Y. C., Kim, Y. K., \& Kim, T. (2014). Perceived corporate social responsibility and donor behavior in college athletics: The mediating effects of trust and commitment. Sport Marketing Quarterly, 23, 73-85.

Laczniak, R., DeCarlo, T., \& Ramaswami, S. (2001). Consumers' responses to negative word-of-mouth communication: An attribution theory perspective. Journal of Consumers Psychology, 11, 57-73. https://doi.org/10.1207/S15327663JCP1101_5

Lee, C., Bang, H., \& Lee, D. (2013). Regaining fans' trust after negative incidents: Fit between responses and nature of incidents. Sport Marketing Quarterly, 22, 235-245.

Lukas, P. (2009). Is this the slippery slope of uniforms? ESPN. Retrieved from http://sports.espn.go.com/espn/page2/story?page=lukas/090602\&amp;sportCat=wnba

Magnusson, P., Wilson, R. T., Zdravkovic, S., Zhou, J. X., \& Westjohn, S. A. (2008). Breaking through the cultural clutter: A comparative assessment of multiple cultural and institutional frameworks. International Marketing Review, 25, 183-201. https://doi.org/10.1108/02651330810866272

Manning, M. (2009). The effects of subjective norms on behaviour in the theory of planned behaviour: A meta analysis. British Journal of Social Psychology, 48, 649-705. https://doi.org/10.1348/014466608X393136

Marsh, H. W., Hau, K. T., \& Wen, Z. (2004). In search of golden rules: Comment on hypothesis-testing approaches to setting cutoff values for fit indexes and dangers in overgeneralizing Hu and Bentler's (1999) findings. Structural Equation Modeling, 11, 320-341. https://doi.org/10.1207/s15328007sem1103_2

Mazodier, M., \& Merunka, D. (2012). Achieving brand loyalty through sponsorship: The role of fit and self-congruity. Journal of the Academy of Marketing Science, 40, 807-820. https://doi.org/10.1007/s11747-011-0285-y

McAllister, M. P., \& Turow, J. (2002). New media and the commercial sphere: Two intersecting trends, five categories of concern. Journal of Broadcasting \& Electronic Media, 46, 505-514. https://doi.org/10.1207/s15506878jobem4604_1

Meenaghan, T. (2001). Understanding sponsorship effects. Psychology and Marketing, 18, 95-122. https://doi.org/10.1002/1520-6793(200102)18:2\%3C95::AID-MAR1001\%3E3.0.CO;2-H

Morwitz, V. G., Steckel, J. H., \& Gupta, A. (2007). When do purchase intentions predict sales? International Journal of Forecasting, 23, 347-364. https://doi.org/10.1016/j.ijforecast.2007.05.015 
O'Reilly, N., Lyberger, M., McCarthy, L., Seguin, B., \& Nadeau, J. (2008). Mega-special-event promotions and intent to purchase: A longitudinal analysis of the Super Bowl. Journal of Sport Management, 22, 392-409. https://doi.org/10.1123/jsm.22.4.392

Palmatier, R. W., Jarvis, C. B., Bechkoff, J. R., \& Kardes, F. R. (2009). The role of customer gratitude in relationship marketing. Journal of Marketing, 73(5), 1-18. https://doi.org/10.1509/jmkg.73.5.1

Premier League. (n. d.). The world's most watched league. Retrieved from http://www.premierleague.com/en-gb/about/the-worlds-most-watched-league.html

Ratten, V. (2011). International sports management: Current trends and future developments. Thunderbird International Business Review, 53, 679-686. https://doi.org/10.1002/tie.20444

Ratten, V., \& Ratten, H. (2011). International sport marketing: Practical and future research implications. Journal of Business \& Industrial Marketing, 26, 614-620. https://doi.org/10.1108/08858621111179886

Samli, A. C. (1994). Towards a model of international consumer behaviour: Key considerations and research avenues. Journal of International Consumer Marketing, 7, 63-85. https://doi.org/10.1300/J046v07n01_05

Santomier, J. (2008). New media, branding and global sports sponsorship. International Journal of Sports Marketing \& Sponsorship, 10(1), 15-28. https://doi.org/10.1108/IJSMS-10-01-2008-B005

Schumacker, R. E., \& Lomax, R. G. (2010). A beginner's guide to structural equation modeling. New York: Routledge.

Schumann, J. H., Wangenheim, F., Stringfellow, A., Yang, Z., Blazevic, V., Praxmarer, S., ... \& Jiménez, F. R. (2010). Cross-cultural differences in the effect of received word-of-mouth referral in relational service exchange. Journal of International Marketing, 18, 62-80. https://doi.org/10.1509/jimk.18.3.62

Singh, S. (2006). Cultural differences in, and influences on, consumers' propensity to adopt innovations. International Marketing Review, 23, 173-191. https://doi.org/10.1108/02651330610660074

Sivakumar, K., \& Nakata, C. (2001). The stampede toward Hofstede's framework: Avoiding the sample design pit in cross-cultural research. Journal of International Business Studies, 32, 555-574. https://doi.org/10.1057/palgrave.jibs.8490984

Spears, N., \& Singh, S. N. (2004). Measuring attitude toward the brand and purchase intentions. Journal of Current Issues \& Research in Advertising, 26, 53-66. https://doi.org/10.1080/10641734.2004.10505164

Sun, B., \& Morwitz, V. G. (2010). Stated intentions and purchase behavior: A unified model. International Journal of Research in Marketing, 27, 356-366. https://doi.org/10.1016/j.jiresmar.2010.06.001

Swanson, S. R., Gwinner, K., Larson, B., \& Janda, S. (2003). Motivations of college student game attendance and word-of-mouth behavior: The impact of gender differences. Sport Marketing Quarterly, 12, 151-162.

Takahashi, K., Ohara, N., Antonucci, T. C., \& Akiyama, H. (2002). Commonalities and differences in close relationships among the Americans and Japanese: A comparison by the individualism/collectivism concept. International Journal of Behavioral Development, 26(5), 453-465. https://doi.org/10.1080/01650250143000418

Thibaut, E., Vos, S., \& Scheerder, J. (2014). Hurdles for sports consumption? The determining factors of household sports expenditures. Sport Management Review, 17, 444-454. https://doi.org/10.1016/j.smr.2013.12.001

Thompson, M. (2014). Adidas pays $\$ 1.3$ billion in Manchester United deal. CNN Money. Retrieved from http://money.cnn.com/2014/07/14/news/companies/adidas-nike-manchester-united/

Tourangeau, R., Rips, L. J., \& Rasinski, K. (2000). Psychometric theories of survey response. Cambridge: Cambridge University Press. https://doi.org/10.1017/CBO9780511819322

Tsiotsou, R. H., \& Alexandris, K. (2009). Delineating the outcomes of sponsorship: Sponsor image, word of mouth, and purchase intentions. International Journal of Retail \& Distribution Management, 37, 358-369. https://doi.org/10.1108/09590550910948583

Wang, M. C. H., Cheng, J. M. S., Purwanto, B. A., \& Erimutri, K. (2011). The determinants of the sports team sponsor's brand equity. International Journal of Market Research, 53, 811-829. https://doi.org/10.2501/IJMR-53-6-811-829

Yoshida, M., \& Heere, B. (2015). Sport marketing in Asia: Exploring trends and issues in the 21st century. Sport Marketing Quarterly, 24, 207-213. 
Yoshida, M., Heere, B., \& Gordon, B. (2015). Predicting behavioral loyalty through community: Why other fans are more important than our own intentions, our satisfaction, and the team itself. Journal of Sport Management, 29, 318-333. https://doi.org/10.1123/jsm.2013-0306

Yousaf, S., \& Huaibin, L. (2013). Profiling consumer behavior in the context of involvement level and demographic factors: Evidence of within-country differences from a developing economy. Journal of Global Marketing, 26(1), 1-17. https://doi.org/10.1080/08911762.2013.779404

\section{Copyrights}

Copyright for this article is retained by the author, with first publication rights granted to the journal.

This is an open-access article distributed under the terms and conditions of the Creative Commons Attribution license (http://creativecommons.org/licenses/by/4.0/). 